\title{
LITERATURA JUVENIL BRASILEIRA E INTERTEXTUALIDADE: O JOVEM E SEUS ENCONTROS COM LEITURAS OUTRAS ${ }^{1}$
}

\author{
Andréia de Oliveira Alencar Iguma (Unigran) \\ Marisa Martins Gama-Khalil (UFU)
}

Resumo: O presente artigo, escrito a quatro mãos - orientanda e orientadora, nasce a partir de reflexões tecidas em uma pesquisa de doutoramento (fase de conclusão) que tem como objetivo analisar as representações dos jovens protagonistas das obras premiadas pela FNLIJ (2000 a 2017). Para este momento, afunilaremos nossos olhares em dois pontos específicos: focalizar acerca da literatura entendida como juvenil e analisar especificamente a contribuição das alusões intertextuais presentes na narrativa O Fazedor de Velhos (2008), do escritor Rodrigo Lacerda. Para tanto, nos apoiaremos em alguns estudiosos que têm contribuído com a consolidação da LJ enquanto sistema, sendo eles, Ceccantini (2010), Ramos (2016), Navas (2016), e a fim de pensar a intertextualidade partiremos da noção de dialogismo de Bakhtin (1997) e do conceito intertextualidade cunhado por Kristeva (1974).

Palavras-chave: Intertextualidade; Juventudes; Literatura Juvenil Brasileira.

Abstract: This article, written by four hands - advisor and advisor, is born from reflections woven in a doctoral research (conclusion phase) that aims to analyze the representations of young protagonists of works awarded by the FNLIJ (2000 to 2017). For this moment, we will focus our views on two specific points: focus on the literature understood as juvenile and specifically analyze the contribution of intertextual allusions present in the narrative $O$ Fazedor de Velhos (2008), by writer Rodrigo Lacerda. To this end, we will rely on some scholars who have contributed to the consolidation of the LJ as a system, namely, Ceccantini (2010), Ramos (2016), Navas (2016), and in order to think of intertextuality we will start from the notion of dialogism of Bakhtin (1997) and the concept intertextuality coined by Kristeva (1974).

Keywords: Intertextuality; Youths; Brazilian Youth Literature.

1 Título em inglês: "Brazilian Youth Literature And Intertextuality: Youth and Its Meetings With Other Readings". 
"Crescer é, de certa forma, se separar das pessoas amadas". (LACERDA, 2008, p.37)

\section{CONSIDERAÇÕES INICIAIS}

$\mathrm{O}$ artigo aqui apresentado insere-se no bojo de nossas reflexões atuais sobre a literatura juvenil brasileira, porque desenvolvemos - orientanda e orientadora - um projeto que tem por objetivo investigar a representação do jovem na literatura juvenil brasileira contemporânea, tomando como objeto de estudo as obras premiadas pela Fundação Nacional do Livro Infantil e Juvenil de 2000 a 2017. No conjunto dessas obras percebemos uma grande incidência de narrativas que têm como recurso discursivo e estético norteador a intertextualidade e a metalinguagem.

Dividiremos a presente reflexão em dois momentos: o primeiro destinado a focalizar o debate sobre a conceituação da juventude e sobre a literatura dirigida ao jovem, e o segundo voltado para algumas considerações sobre a narrativa O Fazedor de Velhos (2008), de autoria do escritor Rodrigo Lacerda.

\section{O JOVEM COMO DEVIR: SEU ESPAÇO SOCIAL E SUA LITERATURA}

Em um importante artigo "A literatura infantil e juvenil: produção brasileira contemporânea" publicado pela revista Letras de Hoje, a pesquisadora Alice Áurea Penteado Martha pontua que: 
Nos últimos quarenta anos, o mercado de publicações para crianças e jovens cresceu em números de títulos e de tiragens, com perfil específico. Na década de 70, período em que Lajolo e Zilberman (1982, p.124) detectaram o desenvolvimento de um comércio especializado, o gênero representava $8 \%$ da tiragem dos lançamentos editoriais. Trinta anos depois, o número de exemplares vendidos já corresponde a $25 \%$ do mercado, se não mais, sempre com expectativa de expansão. Tal crescimento pode ser justificado por investimentos de editoras e livrarias, empreendedoras no que tange ao aspecto editorial e mercadológico, e também por maciços investimentos do Governo Federal, que vem promovendo, com a aquisição regular de livros para crianças e jovens, a duplicação da produção anual, que costumava ser algo em torno de 30 milhões. $(2008$, p.9)

Em recente simpósio na Universidade de Aveiro Portugal $^{2}$, nascido com o propósito de agrupar diferentes estudiosos da literatura juvenil, com olhares e perspectivas distintas, a professora e pesquisadora Ana Margarida Ramos proferiu que, em relação ao Brasil, Espanha e Portugal, estamos vivendo (sendo) a quarta geração de estudiosos de literatura juvenil, e que, por se tratar de um campo tão recente, há muito trabalho a ser feito. Em consonância a

2 O evento aconteceu em abril de 2018 na Universidade de Aveiro e abrigou pesquisadores da Espanha, Portugal e Brasil. Como resultado, alguns textos foram selecionados a fim de comporem um livro que foi lançado em abril de 2019, no qual consta um capítulo nosso. 
fala da professora Martha (2008), corrobora-se que foi nos últimos quarenta anos que o mercado de publicações para crianças e jovens cresceu significativamente, o que culmina com o boom da literatura infantil no Brasil e a consolidação dos escritores conhecidos como herdeiros de Lobato.

Em terras brasileiras, a literatura juvenil, começa a ter uma maior expressividade no final da década de 1970. A pesquisadora Eliana Yunes (2000, p.25) levanta "a hipótese de que os leitores infantis formados na década de 70 teriam se convertido nos leitores juvenis da década de 80 , num fenômeno muito astutamente percebido pelas editoras". A aparição da literatura juvenil se consolida por meio de prêmios de prestígio, dissertações e teses de doutoramento que legitimam sua existência enquanto sistema literário com vida própria, uma vez que a literatura infantil já havia conquistado sua permanência, e, por algum tempo, não havia distinção entre ambas, sendo tratadas como literatura infantojuvenil. A inserção da disciplina de literatura infantojuvenil nas estruturas curriculares de diferentes universidades espalhadas pelo Brasil também contribuiu para a sua difusão.

No caso brasileiro, a consolidação da literatura juvenil como gênero razoavelmente autônomo - em oposição à literatura infantil - deu-se por volta de meados da década de 
70 , quando passa a contar com um conjunto relevante de autores e de obras associados especificamente a um público leitor jovem e ocorre a legitimação do campo por instituições literárias que concedem prêmios na modalidade literatura juvenil ou se voltam à produção regular de pesquisa na área. (CECCANTINI, 2010, p.80)

O excerto integra o trabalho basilar "Uma estética da formação: vinte anos de literatura juvenil brasileira premiada (1978-1997)", resultado da tese de doutoramento do professor João Luís Cardoso Tápias Ceccantini, defendida no ano de 2000, sob orientação do professor Carlos Erivany Fantinati, no Programa de Pós-Graduação na área de Literaturas de Língua Portuguesa da Universidade Estadual de São Paulo - UNESP - campus de Assis. A pesquisa tem contribuído, desde então, com diversos pesquisadores que se desdobram acerca da temática. O estudo, organizado em dois tomos, faz um percurso sobre duas décadas (1978 a 1997) de produção das obras premiadas na categoria juvenil por meio da Câmara Brasileira do Livro - CBL (prêmio Jabuti), da Fundação Nacional do Livro Infantil e Juvenil - FNLIJ - e da Associação Paulista de Críticos das Artes - APCA -, totalizando vinte e sete narrativas como corpus da pesquisa. O autor elenca o seguinte argumento sobre o recorte feito para estabelecer sua base de investigação: “optei por trabalhar apenas com o gênero narrativo, privilegiando as 'narrativas 
longas'" (CECCANTINI, 2010, p.25). Em relação ao recorte temporal, a justificativa fornecida é a de que:

Adotei o ano de 1978 para iniciar o período contemplado pelo corpus de obras objeto de análise, como emblemático da força que o juvenil adquire no contexto de nossa literatura nesse momento, ou seja, não apenas pelo crescimento do número de títulos lançados no mercado, mas porque esse aspecto se reflete também nos mecanismos de legitimação do fenômeno literário. (CECCANTINI, 2010, p.50)

Indubitavelmente, o final da década de 1970 é conhecido como o boom da literatura infantil. Para tanto, é importante pensar o que estava acontecendo no país naquele período e o que ajudou a impulsioná-lo, especialmente, no âmbito literário. Em Confinamento cultural, infância e leitura, o pesquisador Edmir Perrotti (1990, p.13) defende a ideia de que, mesmo com um retardo temporal, começávamos a perceber "a leitura enquanto comportamento a ser difundido e praticado cotidianamente por toda a população brasileira", o que justificou a inserção de diferentes campanhas a favor de "aproximar crianças e jovens do livro e da leitura", contribuindo significativamente com o processo de reflexão sobre uma produção literária nossa que se distanciasse dos modelos moralistas copiados da Europa, ainda tão presentes em nossas escolas. 
Uma nova geração de escritores começou a ganhar visibilidade, principalmente os herdeiros de Lobato, que hoje constituem o cânone da literatura infantil e juvenil brasileira, responsáveis por obras que vão além da didatização e do utilitarismo propostos pelo sistema educacional, uma vez que um dos pontos fragilizadores da legitimação das literaturas infantil e juvenil enquanto arte é sua relação simbiótica com o espaço escolar.

Outro fator que colaborou com a intensificação da produção literária dirigida para crianças e jovens foi a promulgação da Lei de Diretrizes e Bases da Educação no 5.692/71, de 11 de agosto de 1971, que ampliou o nível de escolaridade: “§2o No ensino de 10 e 20 graus dar-se-á especial relevo ao estudo da língua nacional, como instrumento de comunicação $e$ como expressão da cultura brasileira" (BRASIL, 1971, s/p. grifo nosso). Na parte realçada é possível perceber ao menos indireta e sugestivamente o incentivo do período em relação à ampliação da cultura por meio da literatura, posto que a "língua nacional" passou a ser concebida como instrumento da propagação da cultura brasileira, o que contribuiu com a expansão de autores e títulos categorizados nos eixos infantil e juvenil.

As premiações selecionadas na tese do professor Ceccantini (2010) são consideradas como instâncias legitimadoras para 
a configuração de diversos sistemas literários, uma vez que o "peso" do selo atribuído anualmente pela FNLIJ, por exemplo, pressupõe que haja qualidade estética. E não é uma coincidência que o aumento do interesse das editoras pelas obras catalogadas como infantil e juvenil passou a crescer justamente no momento em que os prêmios criam e/ou intensificam o prestígio por essas categorias, impulsionando de certa forma o surgimento de escritores.

A especialista Maria Antonieta Cunha defende que "toda obra literária para crianças pode ser lida [...] pelo adulto: ela é também para crianças. A literatura para adultos, ao contrário, só serve a eles" (1991, p.70). Nesse caso, a estudiosa se refere à literatura infantil, porém utilizaremos essa reflexão para abordar a problemática que envolve o adjetivo juvenil quando associado ao substantivo literatura. Para tanto, concordamos com Cunha ao validar que a literatura destinada às crianças extrapola a faixa etária estipulada na ficha catalográfica ao ir ao encontro de múltiplos leitores, independentemente da idade. Contudo, discordamos, em parte, quando a autora é categórica ao pontuar que a literatura "para adultos" não "serve" para crianças, porque, conforme Michèle Petit pontua, "é impossível prever quais serão os livros aptos a ajudar alguém a se descobrir ou a 
se construir" (2013, p.48), por isso a importância em ofertar títulos diferentes prezando pela qualidade estética. Há certa hiperbolização no referido argumento de Cunha e por isso compreendemos parte do seu sentido; a hipérbole, como é de se esperar, desencadeia uma generalização, entretanto percebemos que esses recursos retóricos emergiram em um tempo no qual era necessário alertar a comunidade, especialmente a acadêmica, sobre a qualidade artística de muitos livros destinados ao público infantil, uma vez que, nessa época - e infelizmente ainda hoje -, a qualidade da produção literária voltada para crianças e jovens era considerada sempre menor que a produção destinada à leitura dos adultos.

Em nossa investigação, pontuamos que a literatura, quando adjetivada com o juvenil, torna-se de interesse de diferentes grupos, desde o mercado até o de pessoas que possam ter similitudes por estarem experimentando fases da vida as quais estejam sendo abordadas nos temas tratados por essa literatura. Entretanto, esse fator não deve ser excludente ao selecionar acervos literários, como, por exemplo, lemos livros de autoria feminina, que no momento social e histórico que o Brasil está vivendo se tornou de mais fácil acesso, mesmo assim não lemos apenas obras escritas 
por mulheres, e essas obras podem (e devem) ser lidas, ainda, por pessoas de outros gêneros. Assim, é a literatura catalogada como juvenil.

Literatura - substantivo. Juvenil - adjetivo. Tira-se o adjetivo, permanece a base, o substantivo literatura; tirase o substantivo e o adjetivo torna-se móvel e passivo de ser integrado a qualquer outro substantivo. Defendemos a tese de que o adjetivo não limita o substantivo, apenas o classifica. Porém, tal como qualquer produção que passe pelo mercado, há literaturas adjetivadas como juvenis com qualidade estética e outras sem qualidade, isto é, sem o trabalho polissêmico com a palavra.

Acreditamos na ideia de que a literatura, independentemente do adjetivo que a ela é agregado seja juvenil, infantil ou de adultos -, deve elaborar-se por intermédio do discurso estético e não do utilitário (PERROTTI, 1986). Todo discurso, sem exceções, é atravessado pelo discurso instrumental, uma vez que traz alguma forma de conhecimento ou saber sobre o mundo, e dependendo do grau de instrumentalidade os discursos se configurarão como utilitários ou estéticos. No caso do discurso utilitário, o instrumental compõe-se como sua base, ou seja, o centro do utilitário, sua força motora, é o instrumental. Por isso o 
discurso utilitário caracteriza alguns gêneros discursivos, como aqueles que fazem parte do livro didático, por exemplo, porquanto naquele espaço discursivo o objetivo é a fixação de saberes. Já o discurso estético tem em sua composição o instrumental, mas esse figura ali secundariamente, apenas em uma condição constitutiva, porque a sua base é o jogo verbal e figurado das palavras, jogo este que tem por fito desencadear múltiplos sentidos. Nesse sentido, não cabe no estético a veiculação de uma verdade ou de um conhecimento único, mas a sugestão de possibilidades de verdade e de entendimento de mundo.

Diante do explicitado indagamos: Por que estamos estudando um sistema literário catalogado e premiado como juvenil, se o adjetivo pode ser retirado?

A problemática do adjetivo se instaura em um preconceito que atravessa séculos no que tange à formação da literatura infantil e, posteriormente, da juvenil, desde sua consolidação no continente europeu com a premissa de apresentar aos (novos) leitores a evolução da Europa e, depois, de um Brasil em ascensão a partir da transição Império/República. Seguindo os ditames da nova sociedade que a revolução burguesa estabeleceu, era necessário reformar a escola existente e propiciar condições para uma educação mais consistente para as crianças e os jovens, e por esse motivo foi 
criada uma literatura dirigida especialmente a esse público. Ocorre que essa vinculação do surgimento da literatura infantil e juvenil com a escola acarreta muitas vezes a ideia equivocada de que essa produção literária deve privilegiar o discurso utilitário e inserir em segundo plano o discurso estético. Essa concepção errônea é consequência de duas crenças simplificadoras: a crença de que crianças e jovens devem apenas ler aquilo que contribuirá diretamente com sua formação, e por isso a literatura a eles dirigida deve ser utilitária, moralizante e didatizadora; e a crença de que eles não são capazes de compreender a linguagem metafórica e figurada constituinte da literatura, e por essa razão os livros de "literatura" que se endereçam a eles tantas vezes carecem de "literatura".

Em se tratando da literatura dirigida aos jovens, é muito comum encontrar, nas diversas editoras, coleções cuja temática se relaciona de forma muito direta à sua formação intelectual e/ou humana. Tais coleções, em diferentes casos, intitulam-se como paradidáticas, porém os livros pertencentes a elas frequentemente são posicionados e nomeados como literários, ainda que careçam de literatura.

Essa alta incidência de livros com uma tendência utilitária talvez tenha por base o entendimento da juventude como 
uma fase etária apenas preparatória: "Certamente, o Direito interpreta parte das práticas sociais e do imaginário coletivo, dividindo a transição da infância à maturidade em 'adolescência' e 'juventude'” (GROPPO, 2016, p.10). A juventude seria, nessa perspectiva de compreensão, uma fase de preparação para a idade adulta e para a sociedade. Trata-se, pois, de uma fase considerada apenas de transição, um tempo que caracteriza o sujeito que se situa entre a infância e a maturidade. Na maior parte das obras que tratam do jovem e da juventude, vemos figurativizada conceitualmente essa imagem da transição. Nessa linha de entendimento, podemos pensar o jovem como um devir, no sentido defendido por Gilles Deleuze (1997), como aquele ser que está sempre em uma zona de indiscernibilidade, em um "entre". Esse entrelugar é normalmente interpretado pela sociedade como um lugar de formação, o que leva o mercado editorial a investir muito em livros destinados à juventude, os quais se constituem basicamente como um espaço de ensinamentos e de regras, tornando-os muito similares aos livros de autoajuda.

Então, o que uma obra precisa ter para se adjetivar como juvenil? Para verticalizarmos o conceito, partiremos de três pontos que construímos por meio do arcabouço de leituras realizadas no decorrer das nossas vidas enquanto pesquisadoras: 
1. A literatura escrita sem considerar o destinatário e depois de ser enviada à editora é catalogada como "juvenil", a partir de associação às temáticas mais comuns ao universo dos adolescentes, tais como: o primeiro beijo, a iniciação sexual, o universo escolar, a convivência com pais, o abuso sexual, a morte, a idade, por exemplo, mesmo que as realidades elencadas não se atribuam a todos os jovens, mas a uma parcela;

2. A literatura escrita tendo em vista o público alvo, porém não se rende às encomendas e mantém o caráter artístico;

3. A literatura escrita sob a "onda do momento". O autor conta com um editor que, por sua vez, encomenda obras com temáticas específicas para atender a demanda que o público e o mercado esperam.

Para discorrer sobre a primeira categoria elencada, trazemos para o cerne da discussão a tese de doutorado intitulada A ficção juvenil brasileira em busca da identidade: a formação do campo e do leitor (2015), defendida pela pesquisadora Raquel Cristina de Souza, no Programa de PósGraduação em Letras Vernáculas da Universidade Federal do Rio de Janeiro (UFRJ), na qual a autora explica que toda obra é escrita tendo em mente o seu destinatário. Alguns autores, 
porém, argumentam que não escrevem pensando em um público definido, contudo a pesquisadora constata que:

$\mathrm{O}$ que eles querem dizer, e com o qual concordamos plenamente, é que não há diferença entre o texto literário infantil ou juvenil e o adulto no que diz respeito ao rendimento literário. A qualidade estética não é o que define um ou outro campo; o que os define são condições diferenciadas de produção, circulação e consumo, que estão baseadas na assunção de um destinatário específico [...]. O que constrange os escritores de literatura infantil e juvenil é o emaranhado de condições externas que parecem predeterminar sua escrita, fato que tende a desmerecer o produto de seu trabalho aos olhos da crítica literária. No entanto, o que esses escritores têm mostrado, década após década, é que todas as limitações aparentes tornam-se no fim desafios criativos que os instigam a um nível de experimentação cada vez mais consciente e que gera resultados estéticos dignos de nota. (SOUZA, 2015, p.22)

No que tange ao segundo ponto, um exemplo relevante é a autora Lygia Bojunga, que em sua carreira soma 22 livros publicados. No conjunto de obras da autora, cujas personagens representam jovens em diferentes situações sociais, ressalta a qualidade de um discurso que prima pelo estético e entrelaça com habilidade temas fraturantes, como a morte, o estupro, a homoafetividade, considerados 
tabus para muitas pessoas em se tratando de uma literatura infantil e juvenil.

A terceira discussão se refere ao abastecimento de grande parte das livrarias. Infelizmente, é comum depararmos com títulos do "momento", que "amanhã" se tornarão obsoletos. Questionamos o porquê de muitos livros com qualidade estética - mas que não tratam de temas "do momento" estarem fora do alcance dos leitores em potencial e serem conhecidos por nós, leitores "autorizados" e não pelos leitores "comuns".

Seria o adjetivo juvenil um desserviço, um caminho ao utilitarismo? Em diversos casos, o leitor não irá buscar uma obra adjetivada como juvenil, porque o termo pode soar pejorativo, tido como algo menor, ou, para "crianças". Mas a quem interessa, de fato, o adjetivo? Aos familiares não leitores que terão uma pré-seleção no momento de "escolher" o que comprar e levar para casa, aos professores que, em boa parte dos casos, não são leitores assíduos; o que valida as editoras considerarem esse público um filão ao direcionar sua produção ao âmbito escolar que, em se tratando do Brasil, ainda é o espaço que mais circulam obras literárias.

Vale mencionar um relevante estudo acerca do papel do crítico. Por que existe o crítico de arte? Por que existe o crítico de literatura? 
Em vez de oferecer sua opinião, um grande crítico permite que os outros formem suas próprias opiniões com base na análise crítica que ele produz. Além disso, essa definição da figura do crítico não deve ser um assunto particular, mas, na medida do possível, um assunto objetivo e estratégico.

(BENJAMIN, 1999, p.548)

É inegável que a literatura juvenil continuará a ser adjetivada pelo mercado, nesse caso, precisamos desenvolver uma crítica séria a respeito e é nesse ponto que comungamos com Benjamin "O que devemos saber sobre um crítico são os valores que ele defende. Ele deve dar essa informação" (1999, p.548).

Para nós, a literatura juvenil traz em sua construção temas e formas que possam interessar o leitor em formação, mas ela também pode atrair outros tipos de leitores, porque um leitor adulto pode se reconhecer ou encontrar nessas obras possibilidades de crescimento humano. Literatura juvenil, em nosso ponto de vista, é aquela que ao retirar o adjetivo continua sendo literatura, na medida em que sua escrita é pautada por uma linguagem polissêmica, pela tematização da condição humana, e pela consequente formação de diferentes sensibilidades. Nessa ótica, o escritor Bartolomeu Campos de Queirós sabiamente expressou: "Deixo as 'mensagens' para os livros de autoajuda e não para os 
literários. Há livro que 'ensina', ou melhor, determina a sina do sujeito. Há livro que concorre para o sujeito reinventar o seu destino" (2005, p.171).

Em um reflexivo artigo, o escritor Ricardo Azevedo problematiza acerca da existência da literatura juvenil, levantando a seguinte questão: "seriam as pessoas de diferentes idades assim tão diferentes entre si a ponto de constituírem grupos homogêneos e estanques?" (2004, p.3).

\section{INTERTEXTUALIDADES NO ENTRELUGAR DO DEVIR- JOVEM}

"Os próprios autores tinham nomes esquisitos e dificeis de pronunciar, como Dostoiévski, Turguêniev, esses bichos. 'Os russos', meu pai me ensinava, rindo".

(LACERDA, 2008, p.18)

Dentre as obras premiadas pela FNLIJ de 2000 a 2017, notamos uma recorrência muito grande de livros que trazem como recurso discursivo e estético de base a intertextualidade.

Em primeiro lugar, ressaltamos que nossa concepção de discurso tem matriz bakhtiniana e por essa razão cremos que o dialogismo é constitutivo a todo ato enunciativo, ou seja, toda palavra é atravessada por palavras de outrem, seja compondo um discurso prosaico, seja um discurso literário (BAKHTIN, 1997). Julia Kristeva, ao forjar a noção de intertextualidade, considera os estudos de Mikhail Bakhtin 
e argumenta que o "diálogo não é só a linguagem assumida pelo sujeito, é uma escritura onde se lê o outro" (KRISTEVA, 1974, p.67). Assim como para Bakhtin não há palavra fora da dialogia, para Kristeva não há texto que não traga em seu tecido verbal a intertextualidade.

Há intertextualidades mais explicitadas e outras que apenas são sugeridas no texto, sendo alusivas, mas o importante é pensarmos que todas as formas intertextuais são de certo modo metadiscursos, porque é o discurso literário que traz em sua trama outros discursos, havendo uma problematização discursiva nesse movimento que se assemelha a uma recitação. Tal recitação sempre terá como consequência estética a ressignificação e, nesse sentido, sempre será muito instigante em contato com leitores.

Diante das obras premiadas pela FNLIJ adotamos como material de análise para o presente artigo a narrativa 0 Fazedor de Velhos (2008), escrita por Rodrigo Lacerda, que foi laureada ainda com outros importantes prêmios, tais como: Programa de Ação Cultural - PMSP - categoria juvenil; Melhor Livro Juvenil da Biblioteca Nacional; Prêmio Jabuti Juvenil; Finalista do Prêmio Chronos - Juvenil. O motivo da escolha da referida obra se justifica em três esferas: primeiro, por estabelecer um diálogo intertextual com diferentes 
obras; segundo, pela personagem protagonista ser jovem; e, ainda, pelo fato de as obras literárias lidas pela personagem protagonista interferirem diretamente em seu processo de formação.

A narrativa se inicia com o narrador-personagem rememorando seu processo de formação enquanto leitor literário: "eu não me lembro direito quando meu pai e minha mãe começaram a me enfiar livros garganta abaixo. Mas foi cedo" (LACERDA, 2008, p.7). Obviamente que a realidade de Pedro, personagem protagonista da narrativa, se distancia da maioria da população brasileira, posto que para muitos o contato com a literatura acontece somente no âmbito escolar. Indubitavelmente, a proximidade com obras literárias desde a idade mais tenra se torna um fator favorável na construção leitora, cooperando de modo positivo com o desenvolvimento da criança, porque além de propiciar "uma multifacetada forma de acesso ao saber" (MACIEL, 2008, p.7), auxilia ainda no processo da formação do leitor.

Nesse prisma, a fim de elucidar tal constatação, trazemos à baila a história de leitura de uma personagem no campo prosaico a fim de estabelecer diálogo com o campo ficcional. José Mindlin, considerado pela crítica especializada como um dos maiores bibliófilos brasileiros, resgatou em sua obra 
No Mundo dos Livros a importância em ter crescido em uma casa que guardava, entre as paredes, uma quantidade significativa de obras literárias: "Meu amor ao livro começou muito cedo, pois tive a sorte de crescer num ambiente cultural. Em casa havia uma boa biblioteca de bons autores estrangeiros e brasileiros" (2009, p.26).

Ressalta, ainda, o papel de seu irmão, três anos mais velho, estudante de arquitetura e leitor assíduo, que sempre o convidava para perambular entre as livrarias locais a procura de novos títulos para suas leituras, em sua construção enquanto leitor. Tal feito contribui para que entre seus 12 e 13 anos já tivesse lido obras tão complexas, como as de Alfredo d'Escragnolle Taunay, Alexandre Herculano e um livro acerca da história da arte:

Do escritor português, me lembro de Lendas e narrativas, do Bobo, e de $O$ monge de Cister. E de Taunay, além de $A$ retirada $d a$ Laguna e Inocência, me lembro de Céus e terras do Brasil e de $\mathrm{O}$ encilhamento. Passava, encantado, das histórias religiosas e medievais de Alexandre Herculano às paisagens ensolaradas do interior do Brasil. Lia isso tudo, de calças curtas, na sala de visitas da casa de meus pais.

(MINDLIN, 2009, p.26)

Conforme lemos no excerto a respeito da história de leitura de Mindlin, constatamos a singularidade de obras 
literárias no processo de formação do leitor, pois entre todos os fatores necessários para a concretização desse processo (mediadores, escola, familiares leitores etc.), o contato com o livro é insubstituível. Para tanto, é necessário que diversos autores e gêneros sejam ofertados, criando, assim, novas possibilidades de leituras, além de contribuir com a ampliação do repertório do leitor em formação.

Tal como Mindlin, campo prosaico, Pedro, campo ficcional, também recebeu influência significativa em seu processo de formação leitora. Ademais, teve ao seu alcance uma diversidade de títulos importantes da literatura brasileira e estrangeira, tal como podemos perceber logo no início da narrativa:

O conteúdo dessas leituras era relativamente variado. Digo relativamente porque as preferências de minha mãe, mesmo sendo variadas entre si, se repetiam sempre. Depois de um tempo, começamos a reconhecer alguns nomes de gente - Castro Alves, José Régio, Gonçalves Dias, João Cabral de Melo Neto, Manuel Bandeira, Fernando Pessoa, Carlos Drummond de Andrade -, e depois alguns nomes de livros e poemas - "Navio Negreiro", "I-Juca-Pirama". Poesia até agora, Mensagem, Rosa do Povo, Carnaval, Auto do Frade, Espumas Flutuantes, "O monstrengo". (LACERDA, 2008, p.7) 
A passagem é um tanto descritiva e, talvez, possa até se tornar cansativa caso o leitor não reconheça as referências intertextuais, ou, parte delas. Além disso, o enredo traz um cenário bastante comum em que se a classe média, um modelo de família tradicional, e os primeiros conflitos enfrentados pela personagem não fogem do horizonte de expectativa quando se pensa no senso comum acerca de temas "juvenis", como a escola e o primeiro amor não correspondido, porém, o narrador nos reserva grandes avanços no decorrer da trama, tanto no que tange à evolução dos conflitos, tanto quanto a inserção de novas personagens que contribuem com a evolução de Pedro. E é por meio do contato com a literatura que a personagem conseguirá enfrentar seus dilemas e se constituir enquanto ser humano.

As estudiosas Ana Margarida Ramos (Portugal) e Diana Navas (Brasil) desenvolveram uma potente pesquisa que resultou no livro Literatura juvenil dos dois lados do Atlântico (2016). No referido material, as escritoras depreendem um capítulo para refletir acerca da intertextualidade enquanto recurso recorrente nas narrativas juvenis e argumentam que "tais discursos desafiam o leitor a desenvolver um pensamento igualmente crítico acerca da textualidade e a assumir um papel bastante ativo no processo da leitura, 
próximo do da coautoria" (RAMOS, NAVAS, 2016, p.114). Desse modo, defendemos que mesmo que o leitor em processo de formação não reconheça todas as alusões e citações intertextuais trazidas na obra $O$ Fazedor de Velhos (2008) ele poderá se sentir aguçado a conhecê-las, ou ainda, a compreender que a personagem protagonista é leitora, tal como ele; reconhecer-se no que lê também é um recurso que se destaca dentro das produções dirigidas ao público juvenil.

No mesmo livro, em que as pesquisadoras abordam a intertextualidade, Ramos e Navas (2016, p.90) discorrem sobre as vozes íntimas na literatura juvenil portuguesa e brasileira e, uma das narrativas adotadas por elas também é $O$ Fazedor de Velhos (2008). Para as autoras é por meio de Pedro,

personagem focalizadora, que conheceremos as outras personagens, o universo ficcional que o circunda, bem como as angústias vivenciadas por um jovem no seu percurso de autognose, de descoberta do seu papel social, das primeiras experiências do amor, da amizade e de difíceis situações da vida.

No Brasil, a pesquisadora Wilma Patricia Maas escreveu o livro O cânone mínimo: o Bildungsroman na história da literatura (2000), que tem contribuído diretamente ao se 
pensar sobre a consolidação da literatura juvenil, em especial, a brasileira, posto que o processo de amadurecimento das personagens que integram as obras do referido sistema literário é recorrente.

A autora se pauta na definição inaugural do conceito cunhado por Morgenstern:

Representa a formação do protagonista em seu início e trajetória até alcançar um determinado grau de perfectibilidade". Uma tal representação deverá promover também "a formação do leitor, de uma maneira mais ampla do que qualquer outro tipo de romance. (2000, p.19)

Trouxemos à baila o referido conceito, mesmo que de maneira rápida, pois nosso objeto de análise pode ser lido como um romance de formação.

Acerca do Bildungsroman na obra O Fazedor de Velhos (2008), Ramos e Navas (2016, p.37) asseveram que "o emprego de uma linguagem essencialmente marcada pela oralidade, em tom de diálogo que envolve o leitor, colabora na construção de uma história que segue a tradição das narrativas de formação (Bildungsroman), recorrente na literatura juvenil".

A partir da citação subsequente é possível ver Pedro, personagem narradora, se reportando ao período de 
sua adolescência. Enquanto leitoras e pesquisadoras, consideremos que é importante esse olhar da personagem jovem-adulta para a personagem jovem-adolescente.

Quando comecei, aos treze anos, minha mãe achou que era cedo demais. Temia que eu acabasse chamando Eça de "Eca" de Queirós. Afinal, os romances dele não apenas costumam ser grandes, 250 páginas no mínimo, como também estão cheios de homens inescrupulosos, de mulheres que traem seus maridos, de figuras invejosas, cruéis etc. Mas nunca tive preguiça de lêlos, e nunca me choquei com absolutamente nada, pelo contrário, adorei rir das situações em que os adultos podiam se meter. Foi como que uma lição para a vida, mas iluminada pelo humor. (LACERDA, 2008, p.15)

A obra de Eça de Queirós, geralmente, começa a ser apresentada no segundo período do Ensino Médio, porém nem sempre os alunos terão acesso ao texto integral e, sim, a fragmentos, posto que, muitas vezes, a vida do autor precede a sua obra em estudos que prezam pelos "ismos", lembrando aqui alguns aspectos defendidos por Todorov em A literatura em Perigo (2010). Ademais, tal como ficcionalizado na escrita lacerdiana, há uma preocupação por parte de muitos pais/ responsáveis e inclusive professores acerca da quantidade de páginas a ser ofertada ao leitor jovem, posto que perante o senso comum, adolescente não gosta de ler. Aqui, caberia 
uma outra discussão que exigiria outro referencial teórico reflexivo, caso optássemos em enveredar por esse caminho, pois seria necessário tratarmos das condições de acesso à leitura e à arte no Brasil; todavia, nosso objetivo é analisar a obra e argumentar o quão prodigioso é o acesso a obras literárias e, como isso pode contribuir satisfatoriamente com a formação de leitores críticos e autônomos. Porém, o que nos desperta no excerto apresentado vai além da quantidade de páginas da obra de um dos mais importantes escritores da língua portuguesa e, sim a crítica à catalogação da obra, como discutido no primeiro subitem deste artigo, afinal, por que a obra não é "endereçada" a um determinado público ela não deverá ser lida por ele?

Ademais, a reflexão que Pedro obtém ao ler a obra de Queirós contribui com uma possível quebra da visão antagônica que nos é apresentada por meio da sociedade moralista em que estamos inseridos. A personagem narradora exclama que: "fiquei muitos anos obcecados por aquela mistura de grande arte com diversão, de temas adultos com leveza, pela combinação que o Eça fazia de personagens bons com defeitos, e de personagens maus com qualidade" (LACERDA, 2008, p.15 - grifo nosso). Nesse prisma, por meio da provocação inserida pela personagem 
narradora, nós leitora, indagamos sobre a divisão entre supostos temas juvenis e de adultos, posto que não é possível limitar a juventude enquanto uma concepção cronológica, mas sim, social, tal como argumenta o sociólogo Luís Antonio Groppo, em Juventude - Ensaios sobre sociologia e história das juventudes modernas:

A juventude é uma categoria social e tal definição faz da juventude algo mais do que uma faixa etária ou uma "classe de idade", no sentido de limites etários restritos - 13 a 20 anos, 17 a 25 anos, 15 a 21 anos etc. [...]. Não existe realmente uma "classe social" formada, ao mesmo tempo, por todos os indivíduos de uma mesma faixa etária. (2000, p.7)

Groppo defende que a juventude não é uma categoria social medida unicamente pela faixa etária e que isso, na verdade, é um fator impossível de acontecer, pois os indivíduos, mesmo pertencentes à mesma faixa etária, não são iguais socialmente. Dessa maneira, pensa-se a juventude como "uma concepção, representação ou criação simbólica, fabricada pelos grupos sociais ou pelos próprios indivíduos tidos como jovens, para significar uma série de comportamentos e atitudes a ela atribuídos" (GROPPO, 2000 , p.8). Nesse prisma, levantamos a problemática que não há uma juventude, mas juventudes plurais, porque é 
inegável que o espaço sociocultural e econômico determina a permanência do indivíduo dentro da categoria juventude ou não.

No portão de embarque rumo a uma viagem com a irmã, Pedro é impedido de adentrar a aeronave, posto que não estava com a carta de autorização dos pais e, como ainda era menor de idade, não poderia embarcar apenas com a irmã que não era sua responsável legal: "Fiquei humilhado. Nada era pior do que ser tratado como criança aos dezesseis anos" (LACERDA, 2008, p.19).

Decidido a embarcar rumo a São Paulo, Pedro teve uma ideia: usar um calhamaço de Shakespeare que havia ganhado de seu pai como passaporte para a idade adulta, reafirmando o senso comum que jovem não lê.

Apresentei a passagem como se nada estivesse acontecendo. E tasquei no balcão o calhamaço de trocentas páginas, em inglês de quinhentos anos atrás. Ela, discretamente, olhou o livro, e eu percebi que tinha causado impacto [...]. Cada segundo demorou um século, até eu ouvir a voz da mulher: Corredor ou janela, senhor? (LACERDA, 2008, p.22)

Após ter impressionado a atendente, Pedro conhece Nabuco, o fazedor de velhos, que passará a ter um papel fundamental na vida da personagem: 
Encarei o velho, percebendo que ele sabia o meu segredo. Eu é que não sabia suas intenções. Tentei manter a calma; no Brasil, pensei, dificilmente ele iria se dar ao trabalho de me entregar. Ser um povo visceralmente desregrado tem que ter alguma compensação! Eu já havia aceitado isso. (LACERDA, 2008, p.23)

A narrativa é rica em diferentes campos, o político, é um deles; mesmo que não seja o foco analítico para este artigo, é importante salientar que o tecido que engendra toda a trama perpassa o social, como o diálogo prodigioso entre juventude e velhice, as críticas acentuadas a quem tem acesso a bens culturais, como o exemplo, Pedro com a literatura.

Pedro, entre trocas de olhares com o sujeito, até então desconhecido, é surpreendido com o início de um diálogo:

- O seu disfarce ficou ótimo [...]. Mas, na minha opinião, o toque de mestre foi o livro. Foi o livro que te envelheceu.

$[\ldots]$

- E o que você acha disso?

- Do quê?

- De ficar mais velho por causa de um livro. (LACERDA, 2008, p.25)

A personagem não consegue responder a pergunta estabelecida pelo interlocutor; nesse momento, ao perceber que o jovem não o responderia, o senhor complementa: 
“- Não deixe de ler o seu Shakespeare" (LACERDA, 2008, p.25). Todavia, nesse momento da narrativa já nos é fornecido os primeiros indícios de como a obra shakespeariana deixaria Rodrigo "mais velho"; não no sentido cronológico, mas sim no processo de amadurecimento.

Anos mais tarde, na formatura da sua turma de Ensino Médio, após descobrir que não era correspondido afetivamente pela sua paixão, Pedro, se reencontra com Nabuco, agora, não com o velho senhor do aeroporto, mas com um respeitado professor que é convidado para proferir o discurso de despedida da turma: "Olhei em volta de novo. As pessoas pareciam embasbacadas [...]. Vendo aquilo, confesso, quase soltei uma gargalhada. Aquele home estava fazendo um antidiscurso. Estava falando exatamente o que ninguém queria ouvir" (LACERDA, 2008, p.38).

Nabuco, o fazedor de velho, não teve um discurso melodramático como os convencionais em cerimônias de formatura, pelo contrário, discursou sobre a vida que dói, os descaminhos, e que, possivelmente, eles não voltariam a se reencontrar e muito menos cumpririam as promessas de amor eterno juradas entre lágrimas e abraços.

Pedro, em um diálogo consigo constatava o óbvio: “A pior coisa para qualquer adolescente é se achar a única pessoa 
infeliz da face da Terra". Porém, entre o dissabor de uma noite que o roubou os sonhos com a menina que gostava, foi em Nabuco que encontrou conforto: "Aquele discurso tinha lavado minha alma [...]. Nada disso era importante. Com o que presenciei naquela noite e, depois, com o que escrutei, a primeira parte da minha vida havia acabado para sempre" (LACERDA, 2008, p.39).

Nesse momento há uma divisão explícita de ciclos dentro da narrativa, em especial, com a vida de Pedro, pois a personagem se despedia entre derrotas, como ver a amiga beijar outro, e vitórias, de ser aprovado no curso de História e dar início à vida acadêmica.

Cursar história não foi uma decisão fácil para Pedro, uma vez que ele se via dividido entre duas paixões: Letras resultado de sua vida de leitor - e História - pela curiosidade em saber como "funcionava" o mundo.

Após ingressar no curso de História, Pedro começa a ter uma crise de identidade e, é nesse momento que "o fazedor de velhos" reaparece em sua vida pela terceira vez, para nesse momento, não mais sair da sua vida. O jovem, em meio a dúvidas, decide recorrer ao professor que discursara em sua formatura:

Aquelas palavras foram ditas a distância, sem nenhum afeto, mas pelo menos iam na direção do meu desejo: saber que profissão 
me faria feliz. Interessado, porém ainda cauteloso, perguntei:

- E qual seria a minha tarefa?

Ele olhou bem nos meus olhos e perguntou:

- Você já leu Shakespeare?

Sorri, em dúvida. Quer dizer, eu tinha certeza de que nunca lera o maldito Shakespeare. Minha dúvida era: o velho Nabuco tinha perguntado aquilo por mera coincidência, ou por que lembrara do dia do aeroporto?

$[\ldots]$

Fiquei meio humilhado. Nem sei por quê, afinal, nada demais nunca ter lido Shakespeare. A maior parte da humanidade nunca leu. (LACERDA, 2008, p.49)

Foi por meio de Rei Lear que o processor Nabuco começou a preparar Pedro para a vida adulta. Por meio de uma conversa nada tranquila, entre gritos e suspiros, o professor desafiou que o jovem lesse o clássico no original, porém Pedro hesitou, pois o livro estava escrito em inglês arcaico; o professor sem muita paciência respondeu que ele mesmo havia demorado cerca de oito anos para realizar a leitura e que não esperava que o jovem demorasse menos do que isso.

Nesse prisma, trazemos a discussão acurada por Bauman (2018) no livro Nascidos em tempos líquidos, no qual discorre acerca de uma geração imediatista, que não está preparada para lidar com conflitos e a respeitar etapas. 
Posto isso, demarcamos por meio das nossas leituras que esse encontro entre "o jovem e o velho" na narrativa convida a sociedade a repensar sobre as relações de troca; de ouvir, para então, falar. Ademais, entre tantas alusões intertextuais importantes dentro da narrativa pomos em relevo agora aquela feita a Shakespeare, na medida em que é justamente pelo processo de enfrentamento do jovem ao realizar a "tarefa" atribuída pelo mestre, que ele começa a viver seu processo de transformação e formação.

Eu estava lá às $2 \mathrm{~h} 45$, mas era como se fosse outra pessoa. Ao tocar a companhia do sobrado, me senti diferente. É verdade. A peça funcionou para mim como o buraco de uma fechadura interior, por onde eu olhei e vi mil coisas antes escondidas. Nem o bom I-Juca, nem o bom Eça, ninguém me deu, como Shakespeare, tamanho soco de humanidade, com tantos vícios, virtudes e sentimentos. (LACERDA, 2008, p.57)

Para as pesquisadoras Ramose Navas "[a] intertextualidade e a paródia são estratégias frequentemente visíveis na produção juvenil" (2016, p.21). Tal como as autoras, vemos, desse modo, a pertinência em exprimir os diálogos intertextuais presentes nas obras de literatura juvenil, escopo do nosso trabalho, pela recorrência de outras "histórias" contadas no corpo de cada obra eleita para integrar este estudo. Em consonância, trazemos a escrita de Regina 
Zilberman, a partir do seu argumento de que os "livros lidos na infância permanecem na memória do adolescente e do adulto, responsáveis que foram por bons momentos aos quais as pessoas não cansam de regressar" (2005, p.9).

Pedro, com certeza, corrobora com a máxima apregoada por Zilberman, afinal, ele nos contou que "acabado o 'meu primeiro Shakespeare', [foi] para os romances do Eça, novamente seguindo a dica da minha eterna leseira encefálica" (LACERDA, 2008, p.69).

\section{REFERÊNCIAS}

AZEVEDO, Ricardo (2004). "Formação de leitores e razões para a literatura". In: SOUZA, Renata Junqueira de. Caminhos para a formação do leitor. São Paulo: DCL, p.38-47.

BAKHTIN, Mikhail (1997). Marxismo e filosofia da linguagem. Michel Lahud e Yara F. Vieira (Trads.). São Paulo: Hucitec.

BENJAMIN, Walter (1999). Selected Writings. Rodney Livingstone et al. (Trad.). Cambridge, MA: Belknap Press.

CECCANTINI, José Luís (2000). Uma estética da formação: vinte anos de literatura juvenil brasileira premiada (1978 - 1997). Unesp/Assis.

(2010). "Conflito de gerações, conflito de cultura: um estudo de personagens em narrativas juvenis brasileiras e galegas". Letras de hoje, Porto Alegre, 45(3), Jul./Set., 80-85.

CUNHA, Maria Antonieta Antunes (1991). Literatura infantil: Teoria \& Prática. São Paulo: Ática.

DELEUZE, Gilles (1997). Crítica e clínica. Peter Pàl Pelbart (Trad.). São Paulo: Editora 34.

GROPPO, Luís Antonio (2000). Juventude: ensaios sobre Sociologia e História das Juventudes Modernas. Rio de Janeiro: Difel. 
(2016). Juventudes: sociologia, cultura e movimentos. Alfenas: Universidade Federal de Alfenas.

KRISTEVA, Julia (1974). Introdução à semanálise. Lúcia H. F. Ferraz (Trad.). São Paulo: Perspectiva.

LACERDA, Rodrigo (2008). O fazedor de velhos. São Paulo: Cosac Naify.

MAAS, Wilma Patricia (2000). O cânone mínimo: o Bildungsroman na história da literatura. São Paulo: Editora UNESP.

MACHADO, Ana Maria (2011). Silenciosa Algazarra: reflexões sobre livros e práticas de leitura. São Paulo: Companhia das Letras.

MACIEL, Francisca Izabel Pereira (2008). “O PNBE e o Ceale: como semear leituras". In: PAIVA, Aparecida; SOARES, Magda (Orgs.). Literatura infantil: políticas e concepções. Belo Horizonte: Autêntica, p.7-20.

MARTHA, Alice Áurea Penteado (2008). "A literatura infantil e juvenil: produção brasileira contemporânea". Letras de hoje, Porto Alegre, 43(2), Abr./Jun, 9-16.

MINDLIN, José (2009). No mundo dos livros. Rio de Janeiro: Agir.

PAULINO, Graça; WALTY, Ivete; CURY, MariaZilda (2005). Intertextualidades: teoria e prática. São Paulo: Formato.

PERROTTI, Edmir (1986). O texto sedutor na literatura infantil. São Paulo: Ícone.

(1990). Confinamento cultural, infância e leitura. São Paulo:

Summus.

PETIT, Michèle (2013). Leituras: do espaço íntimo ao espaço público. Celina Olga (Trad.). São Paulo: Editora 34.

QUEIRÓS, Bartolomeu Campos de (2005). "Leitura, um diálogo subjetivo". In: OLIVEIRA, leda de. O que é qualidade em literatura infantil e juvenil?: com a palavra o escritor. São Paulo: DCL, p.171.

RAMOS, Ana Margarida; NAVAS, Diana (2016). Literatura juvenil dos dois lados do Atlântico. Palmela: Tropelias \& Companhia.

SOUZA, Raquel Cristina (2015). A ficção juvenil brasileira em busca da identidade: a formação do campo e do leitor. (Tese - Doutorado em 
Literatura Brasileira). Programa de Pós-Graduação em Letras Vernáculas da Universidade Federal do Rio de Janeiro, Rio de Janeiro.

ZILBERMAN, Regina (2005). Como e por que ler a literatura infantil brasileira. Rio de Janeiro: Objetiva.

Andréia de Oliveira Alencar Iguma é Doutora em Estudos Literários pela Universidade Federal de Uberlândia (UFU); Mestre em Letras (Literatura e Práticas Culturais) pela Universidade Federal da Grande Dourados (UFGD) em 2012; Graduada em Letras também pela UFGD em 2007. Professora formadora na Travessia Literária - Assessoria Educacional. Integrante ativa do comitê do PROLER na cidade de Dourados - MS. É professora do curso de Letras do Centro Universitário da Grande Dourados - UNIGRAN. Atua principalmente nos seguintes temas: críticas literárias, literatura e ensino, vertentes do insólito e literatura infantil e juvenil.

Marisa Martins Gama-Khalil é Doutora em Estudos Literários pela Universidade Estadual Paulista Júlio de Mesquita Filho/Araraquara (2001). Trabalhou de 1987 a 2006 na Universidade Federal de Rondônia. Atualmente, é professora da Universidade Federal de Uberlândia, onde atua na graduação em Letras, no Programa de Pós-Graduação em Estudos Literários e no Mestrado Profissional em Letras. É líder do Grupo de Pesquisas em Espacialidades Artísticas/CNPq e pesquisadora Produtividade em Pesquisa - CNPq. É membro do GT da ANPOLL Vertentes do Insólito Ficcional. É coordenadora do CENA (Colóquio de Estudos em Narrativa), evento realizado bienalmente na UFU. Realizou o Estágio Sênior Pós-Doutoral na Universidade de Coimbra com projeto contemplado com bolsa CAPES. Atualmente faz parte do núcleo de investigadores do Centro de Literatura Portuguesa da Universidade de Coimbra. Tem livros, artigos e capítulos de livro publicados, com ênfase nas reflexões sobre o espaço ficcional e sobre a narrativa fantástica; nas questões inerentes à literatura infantil e juvenil e ao letramento literário; bem como nas relações plausíveis entre Teoria Literária e Análise do Discurso. 